\title{
The UC Global Food Initiative
}

T his special issue of California Agriculture features news and research articles illustrating the breadth of activities and research that make up the UC Global Food Initiative (GFI).

Launched in 2014 by President Janet Napolitano and UC's 10 chancellors, the GFI's mission is to align the university's research, outreach and internal operations to develop, demonstrate and share scalable solutions for food security, health and sustainability. The GFI is administered by the UC Office of the President and involves all 10 UC campuses, UC Agriculture and Natural Resources and Lawrence Berkeley National Laboratory.

In practice, the GFI is a collection of programs with common goals. The initiative has convened more than 20 committees made up of UC researchers, faculty, staff and students to document best practices and develop agricultural extension fellowship program, and the Communication, Literacy \& Education for Agricultural Research (CLEAR) program, which is preparing the next generation of science communicators.

The news articles that follow highlight the work of six of the GFI's topical committees: urban agriculture and food disparities, food access and basic needs on campuses, food hub collaborative learning (connecting local growers with institutional food service), experiential learning, zero waste dining, and the international Research and Innovation Fellowship for Agriculture.

The 10 peer-reviewed articles in this issue report on a range of subjects relevant to the goals of the GFI: sustainable food production, building agricultural resilience to climate change, reducing greenhouse gas emissions from agriculture, the complexities of pest management, improving food access and reducing food insecurity on campuses and in vulnerable communities, and increasing opportunities for local sourcing of foods.

The issue was guided by California Agriculture Associate Editor Lorrene Ritchie, director of the UC ANR Nutrition Policy Institute, and GFI Program Manager Gale Sheean-Remotto. A panel of seven guest editors reviewed abstracts submitted in response to a call for papers for this issue: Amy Beaudreault, UC Davis World Food Center; Gail Feenstra, UC ANR / UC Davis Sustainable Agriculture Research and Education Program; Clare Gupta, UC ANR / UC Davis Department of Human Ecology; Rose Hayden-Smith, UC ANR / UCOP, founding curatoolkits around various food issues, along with funding targeted research. It has spurred dialogue by launching the influential UC Food Observer blog; producing Mark Bittman: California Matters, a video series hosted by the renowned food writer; and hosting the inaugural California Higher Education Food Summit. And it has supported the development of UC students through more than 200 GFI fellowships, an international tor of the UC Food Observer; Peter Nico, LBNL Earth and Environmental Sciences; and Michael Roberts and Tiana Carriedo, UCLA School of Law Resnick Program for Food Law and Policy. CA 